
Jun Yao*

\title{
Gas flow regimes judgement in nanoporous media by digital core analysis
}

https://doi.org/10.1515/phys-2018-0062

Received Dec 19, 2017; accepted Jun 12, 2018

Abstract: A method to judge shale gas flow regimes based on digital core analysis is proposed in this work. Firstly, three-dimensional shale digital cores in an anonymous shale formation in the Sichuan Basin are reconstructed by a Markov Chain Monte Carlo (MCMC) algorithm based on two-dimensional Scanning Electron Microscope (SEM) images. Then a voxel-based method is proposed to calculate the characteristic length of the three-dimensional shale digital core. The Knudsen number for three-dimensional shale digital cores is calculated by the ratio of the molecular mean free path to the characteristic length and is used to judge the flow regimes under different reservoir conditions. The results indicate that shale gas flow regimes are mainly located at the slip flow and transition flow region. Furthermore, adsorption has no obvious influence on the free gas flow regimes. Because adsorption only exists in organic pores, three-dimensional inorganic pores and organic pores in the Haynesville shale formation are reconstructed by a MCMC algorithm based on twodimensional SEM images. The characteristic lengths of the three-dimensional inorganic pores and three-dimensional organic pores are both calculated and gas flow regimes in organic pores and inorganic pores are judged.

Keywords: shale gas; digital core; flow regimes; characteristic length; nanoporous media

PACS: $51.20 .+\mathrm{d}, 91.60 . \mathrm{Np}$

\footnotetext{
${ }^{\star}$ Corresponding Author: Jun Yao: Research Centre of Multiphase Flow in Porous Media, China University of Petroleum (East China), China; Email: RCOGFR_UPC@126.com

Wenhui Song: State Key Laboratory of Shale Oil and Gas Enrichment Mechanisms and Effective Development; Research Centre of Multiphase Flow in Porous Media, China University of Petroleum (East China), China; Email: song_wen_hui @hotmail.com Hua Liu: State Key Laboratory of Shale Oil and Gas Enrichment Mechanisms and Effective Development; Sinopec Petroleum Exploration and Production Research Institute, Beijing 100083, P.R. China; Email: swh9081@163.com
}

\section{Introduction}

With the rapid decline in conventional reserves, unconventional resources such as tight gas and shale gas reservoirs play an increasingly important role in the North American energy industry and have gradually become a key component of the world energy supply [1-3]. In shale gas reservoirs, gas is stored in organic pores and inorganic pores with nm-scale pore size and extremely low matrix intrinsic permeability [4-7]. Zou et al. [8] reported that pore sizes in shale gas reservoirs range from 1 to $200 \mathrm{~nm}$ and that shale matrix intrinsic permeability ranges from $10^{-9}$ to $10^{-3} \times 10^{-15} \mathrm{~m}^{2}[9,10]$. Gas flows in the forms of free gas and adsorbed gas in an organic pore system, while gas flows in the form of free gas in an inorganic pore system [11-13]. The size of shale nanopores approach the molecular mean free path. Therefore, the continuity assumption becomes invalid [14-16]. The Knudsen number is defined as the ratio of the molecular mean free path to the pore radius $[17,18]$. At different Knudsen numbers, the corresponding gas flow regime in Figure 1 differs.

Lin et al. [19] reviewed recent advances on understanding gas flow processes in unconventional porous rocks. Javadpour [20] described gas flows in the forms of Knudsen diffusion and slip flow regime and proposed a model for gas flow in a nanopore duct. Darabi and Javad-

Weihong Wang: State Key Laboratory of Shale Oil and Gas Enrichment Mechanisms and Effective Development; Sinopec Petroleum Exploration and Production Research Institute, Beijing 100083, P.R. China; Email: yaojun_upc@163.com

Jianlin Zhao: Research Centre of Multiphase Flow in Porous Media, China University of Petroleum (East China), China;

Email: zjlsetoff@163.com

Hai Sun: Research Centre of Multiphase Flow in Porous Media, China University of Petroleum (East China), China;

Email: sunhaiphd_upc@163.com

Dongying Wang: Research Centre of Multiphase Flow in Porous Media, China University of Petroleum (East China), China;

Email: dongying.upc@gmail.com

Yang Li: Department of Oilfield Exploration \& Development, Sinopec, China; Email: yangli_upc@126.com

○ Open Access. (c) 2018 W. Song et al., published by De Gruyter. (cc) BY-NC-ND NonCommercial-NoDerivatives 4.0 License 


\begin{tabular}{|c|c|c|c|}
\hline \multicolumn{4}{|c|}{ Boltzmann equation } \\
\hline \multicolumn{2}{|c|}{ Navier-Stokes equation } & \multirow[b]{4}{*}{ Transition Flow } & \multirow[b]{4}{*}{ Free molecular flow } \\
\hline Non-slip condition & Slip condition & & \\
\hline Darcy Law & \multirow[b]{2}{*}{ Slip flow } & & \\
\hline Continuum Flow & & & \\
\hline
\end{tabular}

Figure 1: Transition of flow regimes based on the Knudsen number

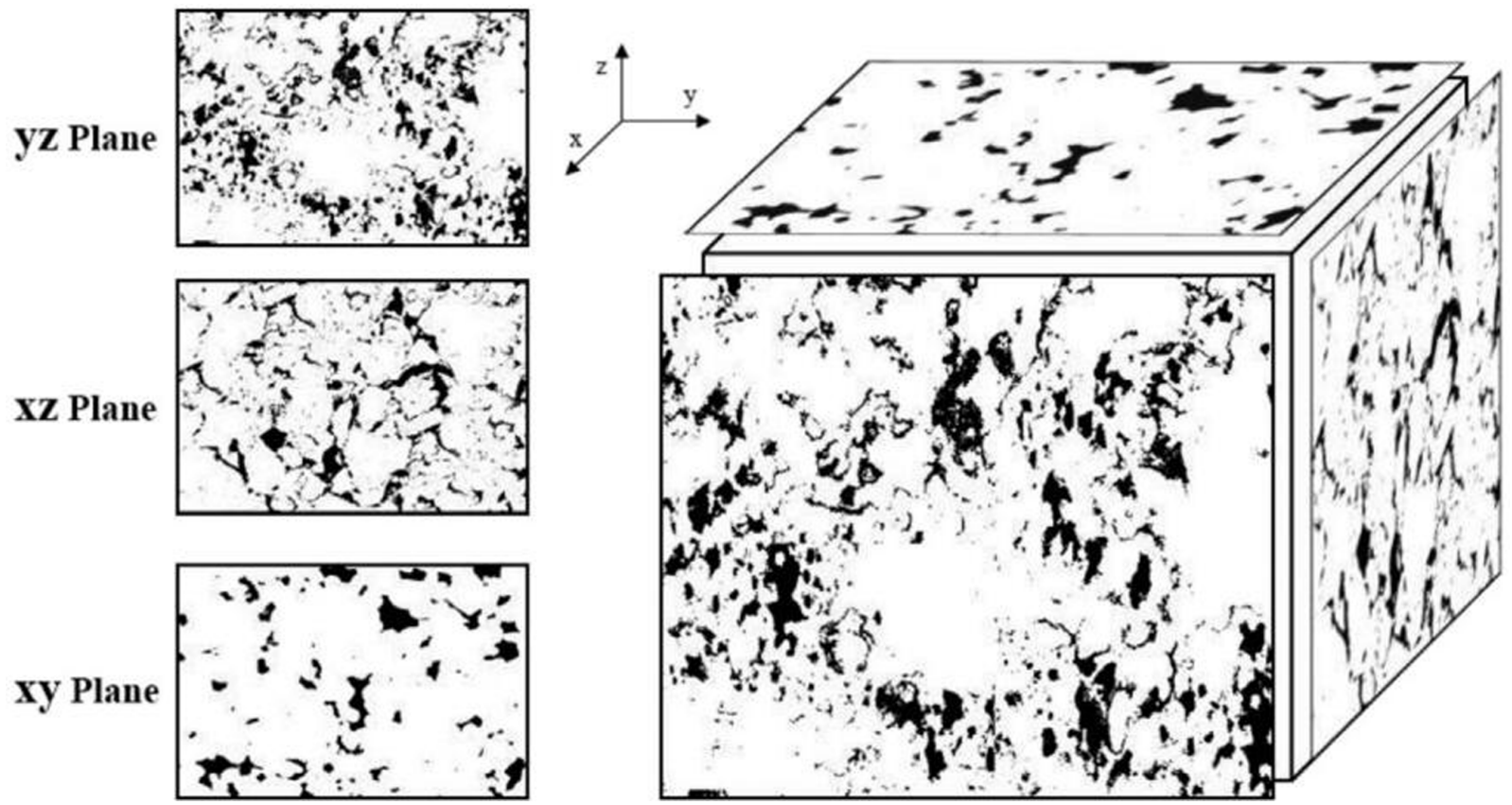

Figure 2: Sketch map of a heterogeneous porous media simulation based on three perpendicular thin sections

pour et al. [21] incorporated Knudsen diffusion and surface roughness into the gas flow model by Maxwell theory. However, the Javadpour model [20] includes one empirical coefficient known as the tangential momentum accommodation coefficient (TMAC) and accurate prediction of TMAC for different shale samples is not available. Beskok and Karniadakis [22] developed a unified Hagen-Poiseuilletype model valid in all flow regimes and this model has been adopted by Civan et al. [18, 23, 24] to consider the intrinsic permeability, porosity, and tortuosity of porous media. Freeman et al. [25] claimed that shale gas flows in the transitional flow regime. Landry et al. [26] deemed that gas flow in nanopores at reservoir pressure - temperature conditions falls within the slip flow and early transition flow regime. Wu et al. [27] considered shale gas flows in the forms of continuum flow, slip flow and transition flow. Sun et al. [28] concluded that Knudsen diffusion can be ignored when pressure is larger than $1 \mathrm{MPa}$. Although there are different viewpoints on shale gas flow in transition flow regime, most of the current studies suggest that shale gas flows in the slip flow regime at typical reservoir conditions $[3,29,30]$.

The estimated ultimate recovery (EUR) of gas reservoirs is highly dependent on the pore structure characteristics [31-36]. Characteristics of pore systems in Sichuan Basin shale formation in China have been studied in literature [37-40]. However, the current analysis and results are mostly based on two-dimensional SEM images and the three dimensional pore structure is not fully understood. Though three dimensional organic matter and in- 
organic matter can be observed by Focused Ion BeamScanning Electron Microscopes (FIB-SEM) [41-44], three dimensional organic pores and inorganic pores cannot be directly imaged and divided due to the limited resolution. On the other hand, the MCMC method is widely used for image processing research [45]. The MCMC method was applied to generate pore space of real heterogeneous porous media [46] and was also used to analyze shale pore structures [47] in our previous study.

Most of the current studies on gas flow in shale needs a predefined gas flow regime based on the Knudsen number to select the corresponding gas flow model. The Knudsen number for three-dimensional porous media is generally defined by the mean free path divided by the characteristic length of porous media. Previous work established a characteristic length analytical solution based on the two dimensional conceptual porous media [48, 49]. However, the characteristic length has not been calculated in the realistic subsurface porous media. With the recent advances in imaging techniques, detailed pore structure can be captured based on digital images, for example SEM and FIBSEM. In this study we propose an algorithm to accurately calculate the characteristic length based on a digital image and Knudsen number for three-dimensional porous media to determine gas flow regimes and flow models. Threedimensional shale digital cores in an anonymous shale formation in Sichuan Basin are first reconstructed by the MCMC algorithm based on two-dimensional SEM images. Then a voxel-based method is proposed to calculate the characteristic length of the shale digital core. The Knudsen number for the three-dimensional shale digital core is calculated by the ratio of the mean free path to the characteristic length and is used to judge the flow regimes under different reservoir conditions. Because adsorption only exists in organic pores, three-dimensional inorganic pores and three-dimensional organic pores are reconstructed respectively by the MCMC algorithm based on two-dimensional SEM images. Characteristic lengths of three-dimensional inorganic pores and three-dimensional organic pores are both calculated and free gas flow regimes in organic pores and inorganic pores are judged. Shale gas permeability at different reservoir conditions is also analyzed.

\section{MCMC digital core reconstruction method}

A Markov chain can be used for describing systems that follow a chain of linked events. Subsequent events depend only on the current state of the system. Suppose $X(t)$ is a known random process describing the state of a process at time $t_{0}$. If the state of random process $X(t)$ in the future time $t\left(t>t_{0}\right)$ only depends on the state at time $t_{0}$ and is uncorrelated with the state before time $t_{0}$, this random process $X(t)$ is called a Markov process. During a Markov process, the relationship between "PAST" and "FUTURE" can be described as "FUTURE" linked to the "PAST" through "NOW", and if "NOW" is confirmed, "FUTURE" is irrelevant to the "PAST". Suppose a system is composed of $n$ voxels $(i=1, \ldots, \mathrm{n})$, and $X=X_{1}, \ldots, X_{n}$ indicates the state of the voxels. Therefore, $X_{i}$ means that site $i$ has a state $x_{i}$. Specifically, for a certain voxel $s, \Lambda \_s$ represents all of the other points except $s$. The neighbor of voxel $s, N_{s}$ must exist and can be described as:

$$
p\left(\chi_{s} \mid \chi\left(\Lambda_{-s}\right)\right) \approx p\left(\chi_{s} \mid \chi\left(N_{s}\right)\right)
$$

Assume $V_{L M N}=\{(l, m, n): 0<l \leq L, 0<m \leq M, 0<n \leq N\}$ represents $L$ rows, $M$ columns, and $N$ layers of a rectangular grid filled with cube voxels. $(i, j, k)$ represents the intersected voxel of row $i$, column $j$ and layer $k$, and its associated state is expressed as $X_{i j k}$. $V_{i j k}$ represents a rectangular parallelepiped array of voxels, and its associated state is expressed as vector $X\left(V_{i j k}\right)$. Any $(i, j, k) \in V_{L M N}$ has the joint probability function:

$$
\begin{aligned}
& p\left(x\left(V_{i j k}\right)\right)= \\
& \prod_{l=2}^{i} \prod_{m=2}^{j} \prod_{n=2}^{k} p\left(x_{l m n} \mid x_{(l-1) m n}, x_{l(m-1) n}, x_{l m(n-1)}\right)
\end{aligned}
$$

The conditional probability of each voxel for its random Markov field is:

$$
\begin{aligned}
& p\left(x_{i j k} \mid\left\{x_{l m n}(l, m, n) \neq(i, j, k)\right\}\right) \\
& =p\left(x_{i j k} \mid\left\{x_{l m n}(l, m, n) \in N(i j k)\right\}\right.
\end{aligned}
$$

In the absence of three-dimensional information, three mutually perpendicular independent twodimensional images can be used to reconstruct a threedimensional chain. The core slice data from three mutually perpendicular planes $x y, y z$ and $x z$ are extracted and the corresponding binary images are obtained. The double voxel method is applied to simultaneously produce two new voxels, i.e. voxel $(i, j, k)$ and $(i, j+1, k)$, during the modeling process. Therefore, the reconstruction steps for the three-dimensional digital core are as follows. The porosity of the horizontal core slices is used as the conditional probability and the voxels on the first line of the first layer are simulated along the y-direction. The second voxel of the first line is simulated using the 2-neighborhood model, and after that, the 3-neighborhood model is used at the beginning of the simulation of the third voxel. Its conditional 


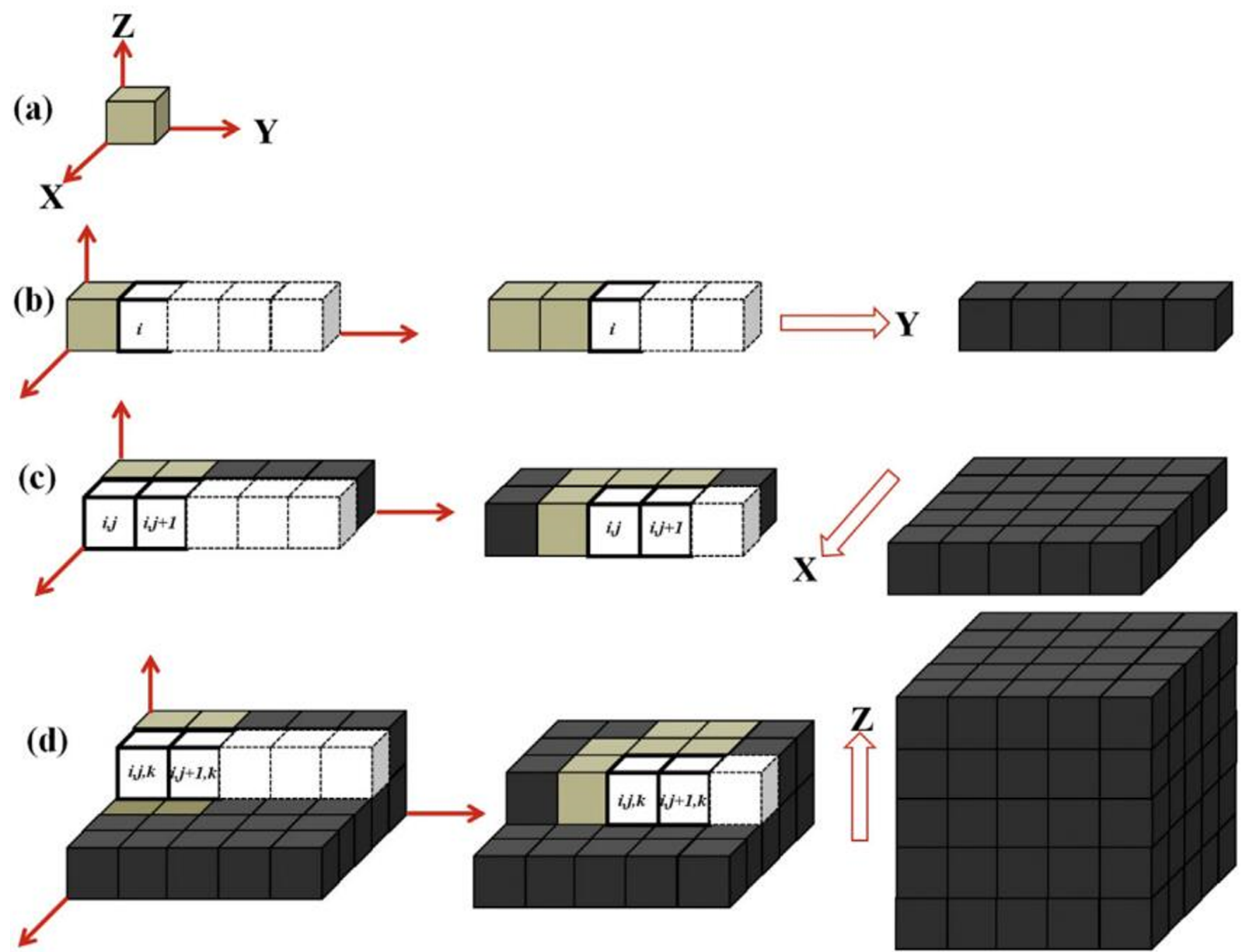

Figure 3: The three dimensional digital core reconstruction process based on the MCMC method (white elements with lines are the "NOW" simulating voxel; white elements with dotted lines are the "FUTURE" simulating voxel; dark elements are the voxels already produced, while light elements are the neighbors of the voxel currently being simulated, and they both belong to "PAST" voxels)

probability is calculated by the two-dimensional core slice on the $x y$ plane (Figure 3(b)). The first layer is simulated along the $x$ direction line by line. For double elements $(i, j)$ and $(i, j+1), 3$ and 4 neighborhoods are used when simulating the edge voxels, and 5 and 6 neighborhoods are used when simulating the internal voxels. The conditional probability is derived by the two-dimensional core slice on the $x y$ plane (Figure 3(c)). Each layer of voxels is simulated along the $Z$-direction and the three-dimensional model is reconstructed (Figure 3(d)).

\section{Reconstruction of Sichuan Basin shale digital core}

Three-dimensional shale digital cores in Figure 5 and Figure 6 are reconstructed based on binary SEM images (Figure 4) using the above mentioned MCMC algorithm. The blue colour represents pore phase and the red color represents matrix phase. In three-dimensional shale digital cores, pore phase is represented by number 0 and matrix is represented by number 1 . Detailed parameters of shale digital cores are given in Table 1.

\section{Voxel based characteristic length calculation method}

For single tubes, the analysis on gas flow regimes has been well studied [20, 50]. The Knudsen number for a single tube and a three-dimensional porous media can be written respectively as:

$$
\begin{aligned}
K_{n} & =\frac{\lambda}{r} \\
K_{n} & =\frac{\lambda}{l_{c}}
\end{aligned}
$$


Table 1: Parameters of shale digital cores

\begin{tabular}{ccccc}
\hline Core number & Geometrical size & Voxel size & Resolution & Porosity \\
\hline 1 & $1096 \mathrm{~nm} \times 1096 \mathrm{~nm} \times 1096 \mathrm{~nm}$ & $100 \times 100 \times 100$ & $10.96 \mathrm{~nm}$ & 0.23 \\
2 & $448 \mathrm{~nm} \times 448 \mathrm{~nm} \times 448 \mathrm{~nm}$ & $100 \times 100 \times 100$ & $4.48 \mathrm{~nm}$ & 0.15 \\
3 & $282 \mathrm{~nm} \times 282 \mathrm{~nm} \times 282 \mathrm{~nm}$ & $100 \times 100 \times 100$ & $2.82 \mathrm{~nm}$ & 0.12 \\
4 & $282 \mathrm{~nm} \times 282 \mathrm{~nm} \times 282 \mathrm{~nm}$ & $100 \times 100 \times 100$ & $2.82 \mathrm{~nm}$ & 0.16 \\
5 & $448 \mathrm{~nm} \times 448 \mathrm{~nm} \times 448 \mathrm{~nm}$ & $100 \times 100 \times 100$ & $4.48 \mathrm{~nm}$ & 0.07 \\
\hline
\end{tabular}

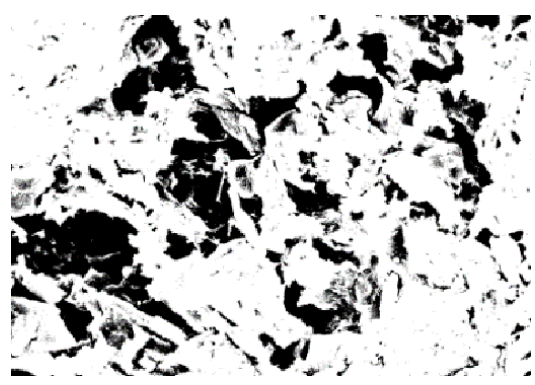

(a) Sample 1

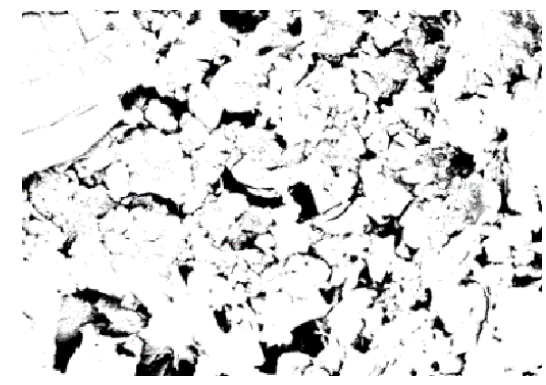

(b) Sample 2

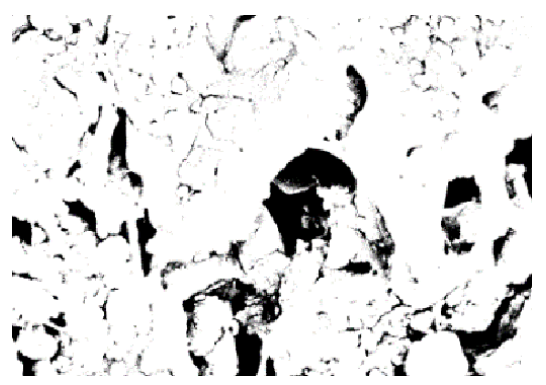

(c) Sample 3

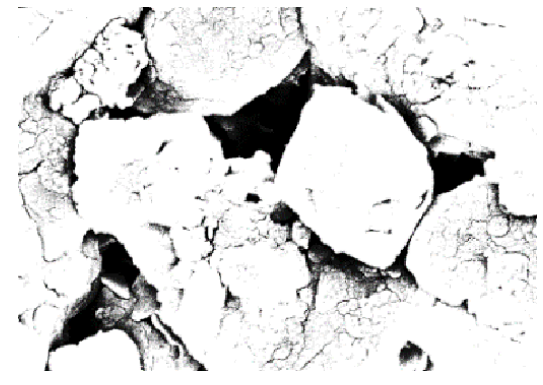

(d) Sample 4

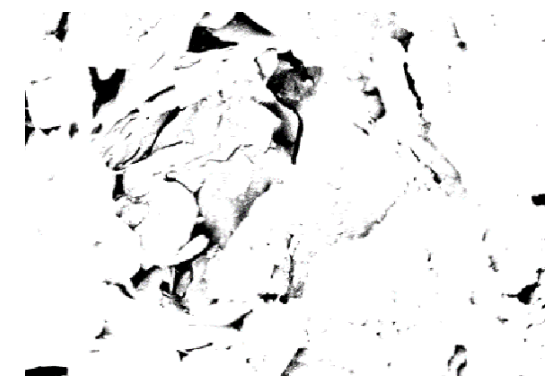

(e) Sample 5

Figure 4: Binary SEM images of shale samples (white represents matrix while black represents pore phases)
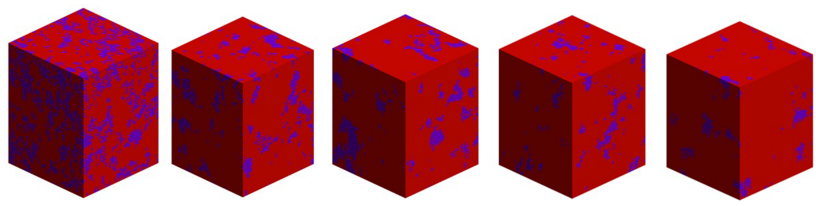

Figure 5: Three dimensional shale digital cores reconstructed by MCMC

$$
\lambda=\frac{k_{B} T}{\sqrt{2} \pi d_{m}^{2} P_{g}}
$$

$l_{c}$ is referred to as the characteristic length of porous media and can be calculated based on the chord length [48]. The chord lengths are those discontinuous lines distributed in pore phase when a line is used to cut porous media. The porous media characteristic length indicates the degree of gas diffusion in porous media and its physical meaning is the free path when gas transports within the porous media. The porous media characteristic length has been
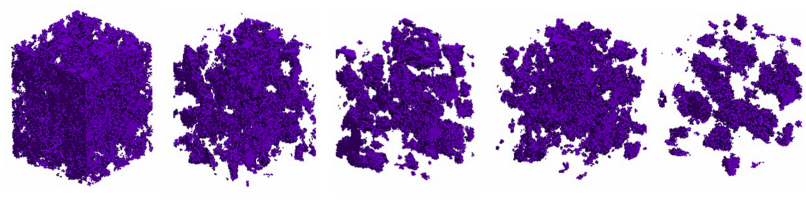

Figure 6: Pore phases of three dimensional shale digital cores

used to analyze gas transport ability in loose packings of spheres [ $[51,52]$ and can be calculated by $[48,49]$ :

$$
l_{c}=\int_{0}^{\infty} z p(z) d z
$$

Chord lengths are the distributions of lengths between intersections of lines with the interface (Figure 7). A chord is then a special line segment with its end points on the interface and all other points in one of the two phases. Here chord lengths in pore phase are calculated. $p(z)$ is the chord length distribution function in pore phases. $p(z) d z$ is 


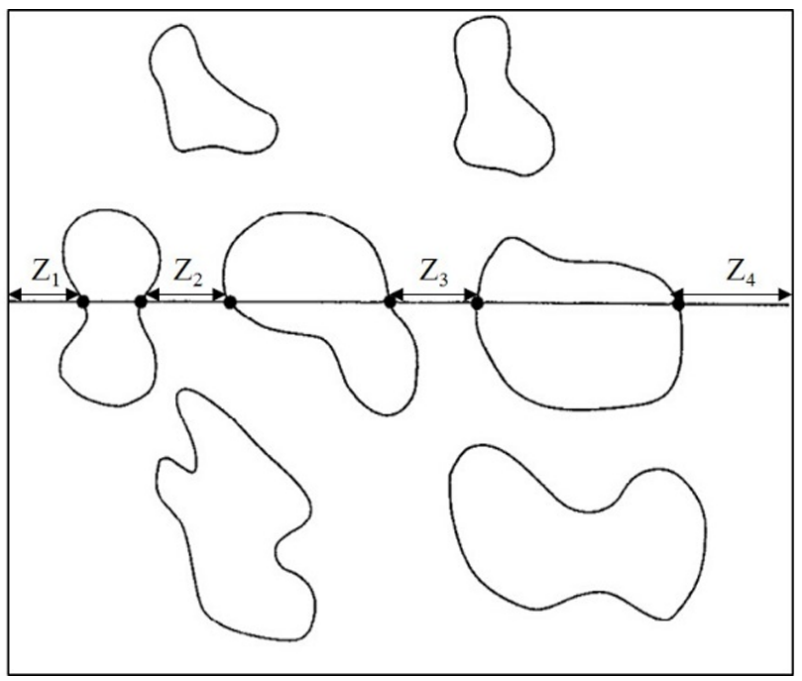

Figure 7: Schematic of chord-length measurements for a cross section of porous media. The chords are defined by intersection of lines with two-phase interface, closed curve area refers to rock matrix [32]

the probability of finding a chord of length between $z$ and $z+d z$ in pore phase.

Previous studies have not applied Equation (5) to real rock samples. Here we propose a method to calculate the characteristic length based on digital image. The chord length in the binary digital image can be represented as the length of continuous number 0 in the pore phase. A regional example in two dimensions is shown in Figure 8, the voxel-based chord length is represented by the number of continuous 0 on red line. In three-dimensional pore phase, the first chord length is measured in the bottom slice on the $X Y$ plane and then the measuring window moves up in the $Z$ direction layer by layer. Finally, chord length for three-dimensional pore phase can be obtained and Equation (8) is used to calculate the characteristic length of the three-dimensional pore phase. A validation of the proposed voxel based characteristic length calculation method can be found in the next section.

$$
l_{c_{-} 3 D}=\int_{0}^{\infty} z_{-} v o l p\left(z_{-} v o l\right) d z_{-} v o l \times \gamma
$$

Gas adsorption is generally assumed to be a monolayer adsorption [53] and can be characterized with the Langmuir isotherm. Considering the influence of an adsorption layer, first adsorbed gas coverage on the pore wall is calculated by Equation (9) and the effective characteristic length of the three-dimensional pore phase is given in Equation (10).

$$
\theta=\frac{P_{g} / P_{L}}{1+P_{g} / P_{L}}
$$

$$
l_{c}\left(P_{g}\right)=l_{C_{-} 3 D}-d_{m} \theta
$$

According to Equation (5), Equation (6), Equation (9) and Equation (10), the Knudsen number without adsorption and with adsorption can be given respectively as:

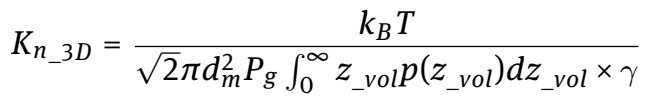

$$
\begin{aligned}
& K_{n \_3 D \_a d s}=
\end{aligned}
$$

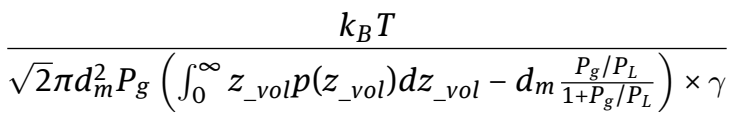

\section{Validation of the proposed voxel based characteristic length calculation method}

The three-dimensional microscale lattice Boltzmann (LB) model with the D3Q19 discrete velocity model developed in our previous study [54] is adopted to simulate gas flow in a shale digital core. The developed LB model can be applied to simulate gas flow in slip flow and transition flow regimes. The basic evolution equation with the BhatnagarGrossKrook (BGK) collision approximation is shown as follows:

$$
\begin{aligned}
& f_{\alpha}\left(r_{s}+e_{\alpha} \delta_{t}, t+\delta_{t}\right)-f_{\alpha}\left(r_{s}, t\right)= \\
& -\frac{1}{\tau}\left(f_{\alpha}-f_{\alpha}^{e q}\right)+\delta_{t} F_{\alpha}
\end{aligned}
$$

Where $f_{\alpha}$ is the density distribution function of $\alpha$ direction; $\alpha=0,1,2, \ldots, 18 ; r_{s}$ is the spatial location of the particles; $e_{\alpha}$ is the velocity of $\alpha$ direction; $t$ is time; $\delta_{t}$ is time step; $\tau$ is the relaxation time; $F_{\alpha}$ is the force term; $f_{\alpha}^{e q}$ is the local equilibrium distribution function of $\alpha$ direction:

$$
f_{\alpha}^{e q}=w_{\alpha} \rho\left[1+\frac{e_{\alpha} u}{c_{s}^{2}}+\frac{\left(e_{\alpha} u\right)^{2}}{2 c_{s}^{4}}-\frac{u^{2}}{2 c_{s}^{2}}\right]
$$

Where $c_{s}$ is the lattice sound speed; $w_{\alpha}$ is the weight factor of $\alpha$ direction. The force term in Equation (13) can be obtained by Hermite expansion. For the D3Q19 model, it can be expressed as [55]:

$$
F_{\alpha}=w_{\alpha} \rho\left[\frac{e_{\alpha} a}{c_{S}^{2}}+\frac{a u:\left(e_{\alpha} e_{\alpha}-c_{S}^{2} I\right)}{c_{S}^{4}}\right]
$$

Where $\boldsymbol{a}$ is the acceleration of the force. For gas flow in shale nanopores, the relaxation time should be determined by the Knudsen number. Considering the microscale effect and the effect of the Knudsen layer, the relaxation time can be expressed as [56]:

$$
\tau_{e}=\frac{1}{2}+\sqrt{\frac{6}{\pi}} K n \psi(K n) N
$$




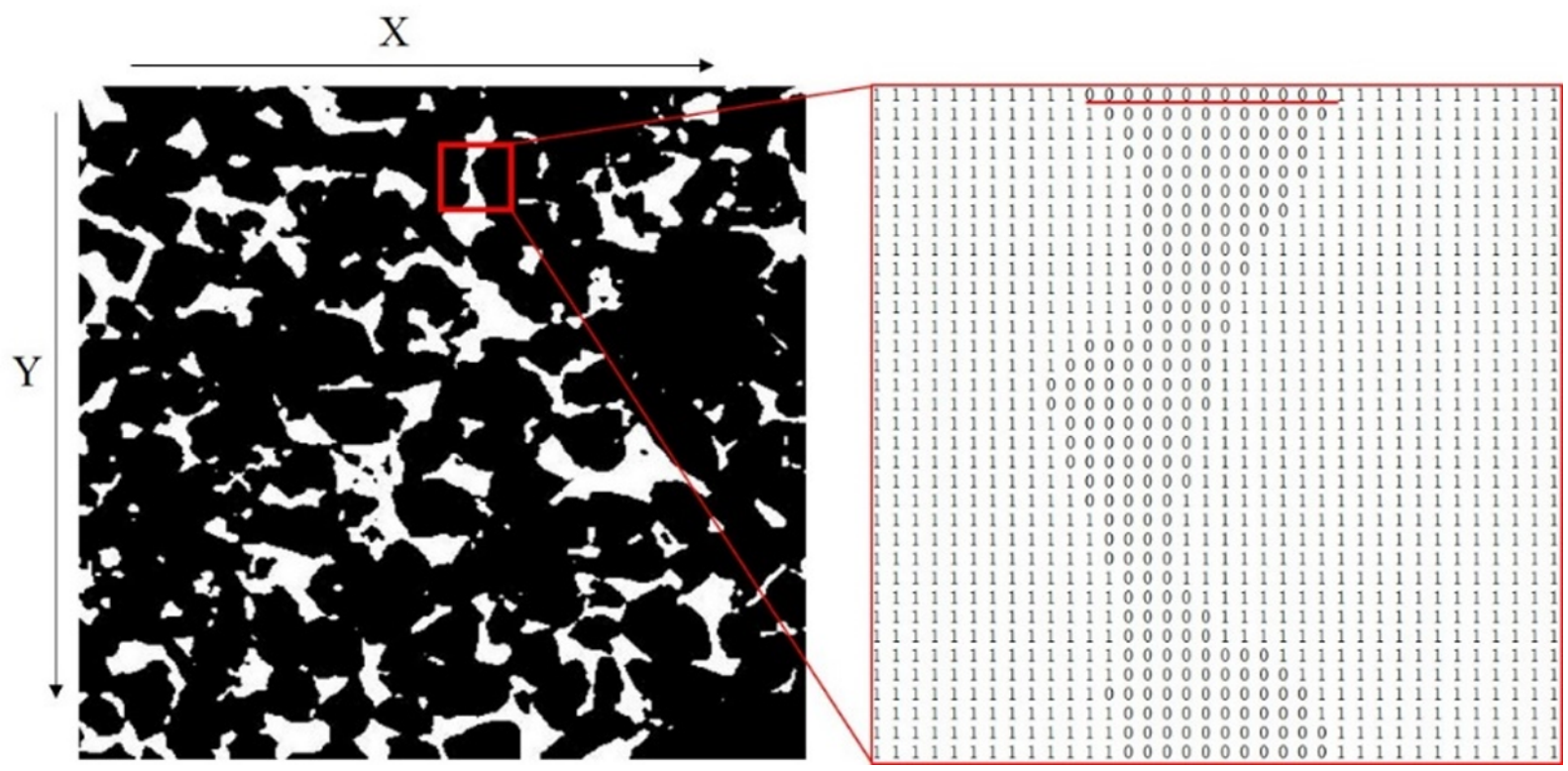

Figure 8: Illustration of chord length measurements in $X Y$ cross section

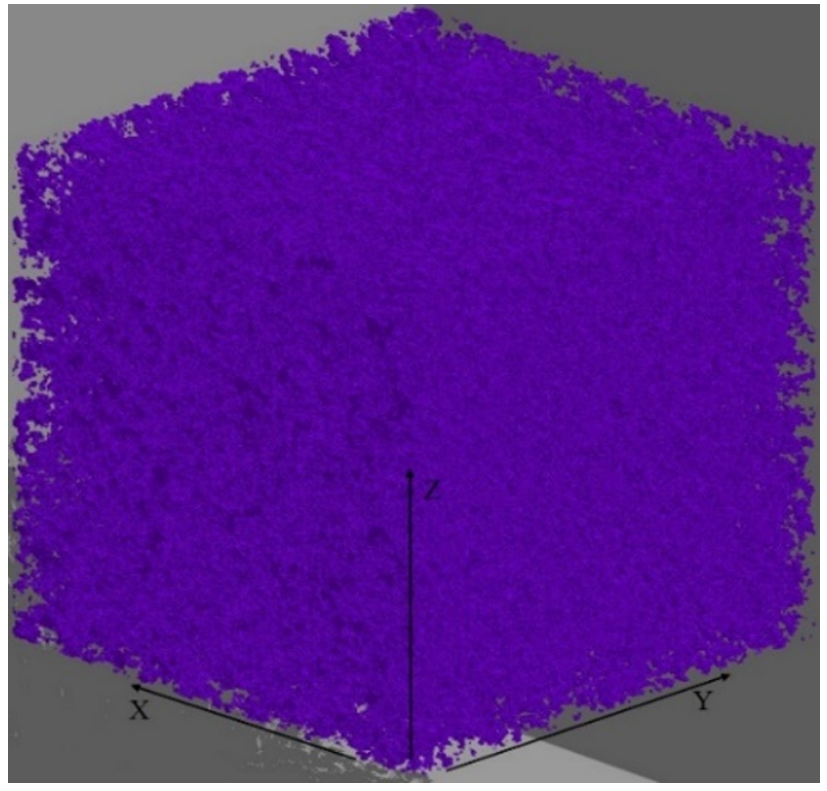

Figure 9: Illustration of chord length measurements in three orthogonal $X, Y, Z$ directions

$\psi(K n)$ is the modification function and equals $1 /(1+2 K n)$; $N$ is the number of lattices occupied by the characteristic length. As the solid boundaries in shale are rough, the diffuse reflection boundary condition is very appropriate for such boundaries. The discrete format of the diffuse reflec- tion boundary condition is expressed as [57]:

$$
\begin{aligned}
& f_{\alpha}=\frac{\sum_{\xi_{\alpha}^{\prime} \cdot n<0}\left|\xi_{\alpha}^{\prime} \cdot n\right| f_{\alpha}^{\prime}}{\sum_{\xi_{\alpha}^{\prime} \cdot n>0}\left|\xi_{\alpha}^{\prime} \cdot n\right| f_{\alpha}^{e q}\left(\rho_{w}, \mu_{w}\right)} f_{\alpha}^{e q}\left(\rho_{w}, \mu_{w}\right), \\
& \left(e_{\alpha}-u_{w}\right) \cdot n>0
\end{aligned}
$$

Where $n$ is the inward unit normal vector; $u_{w}$ is the wall velocity; the subscript $w$ represents the solid walls; $f_{\alpha}^{\prime}$ is the distribution function after streaming. Gas flux $Q$ is calculated in the outlets and the Darcy equation is applied to calculate gas permeability:

$$
k_{1}=\frac{Q \mu L}{A \Delta P}
$$

Detailed parameters are given in Table 2. The studied shale digital core is shown in Figure 10 and pressure drop distribution on the shale digital core is shown in Figure 11. The calculated permeability $k_{1}$ is $2.7831 \times 10^{-7} \mu \mathrm{m}^{2}$.

The Civan et al. model [18] in Equation (19) is applied to calculate gas permeability in slip flow regime and transition flow regime. The characteristic length is calculated based on the proposed voxel based method in Equation (8) and the Knudsen number is calculated using Equation (11).

$$
k_{2}=\frac{\phi r_{c}^{2}}{8 \tau} f(K n)=\frac{\phi l_{c}^{2}}{32 \tau} f(K n)
$$

The flow condition function $f\left(K_{n}\right)$ is given by [22]:

$$
f\left(K_{n}\right)=\left(1+\alpha K_{n}\right)\left(1+\frac{4 K_{n}}{1-\beta K_{n}}\right)
$$


Table 2: Parameters of shale digital core for model validation

\begin{tabular}{cc}
\hline Properties & Value \\
\hline Pressure $\mathrm{P}_{\mathrm{g}} / \mathrm{MPa}$ & 30 \\
Temperature $/ \mathrm{K}$ & 358 \\
Voxel size & $100 \times 100 \times 100$ \\
Porosity & 0.14 \\
Tortuosity & 2.2 \\
Resolution $\gamma / \mathrm{m}$ & $2 \times 10^{-9}$ \\
Pressure gradient $/ \mathrm{MPa} / \mathrm{m}$ & 0.1 \\
Pressure drop on the shale digital & 0.02 \\
core $/ \mathrm{Pa}$ & \\
\hline
\end{tabular}

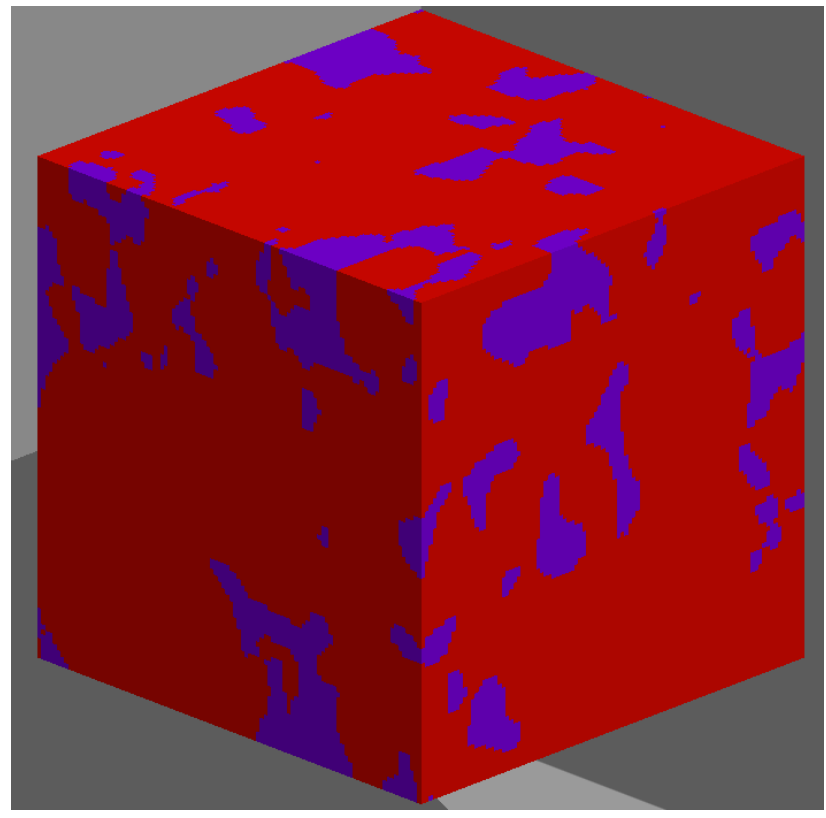

Figure 10: Shale digital core (blue represents pore phase, red represents matrix phase)

The parameter $\alpha$ in Equation (20) is a dimensionless rarefaction coefficient and can be written as:

$$
\alpha=\frac{128}{15 \pi^{2}} \tan ^{-1}\left[4.0 K_{n}^{0.4}\right]
$$

Though the slip coefficient $\beta=-1$ is initially considered only to be applicable to slip flow condition, evidence from the DSMC simulations and Boltzmann solutions [58] showed that $\beta=-1$ is valid within the full range of flow regimes. The calculated characteristic length in Equation (8) is $11.72 \mathrm{~nm}$ and the calculated permeability $k_{2}$ in Equation (19) is $2.9784 \times 10^{-7} \mu \mathrm{m}^{2} . k_{2}$ is very close to $k_{1}$ which suggests the proposed characteristic length calculation algorithm is correct.

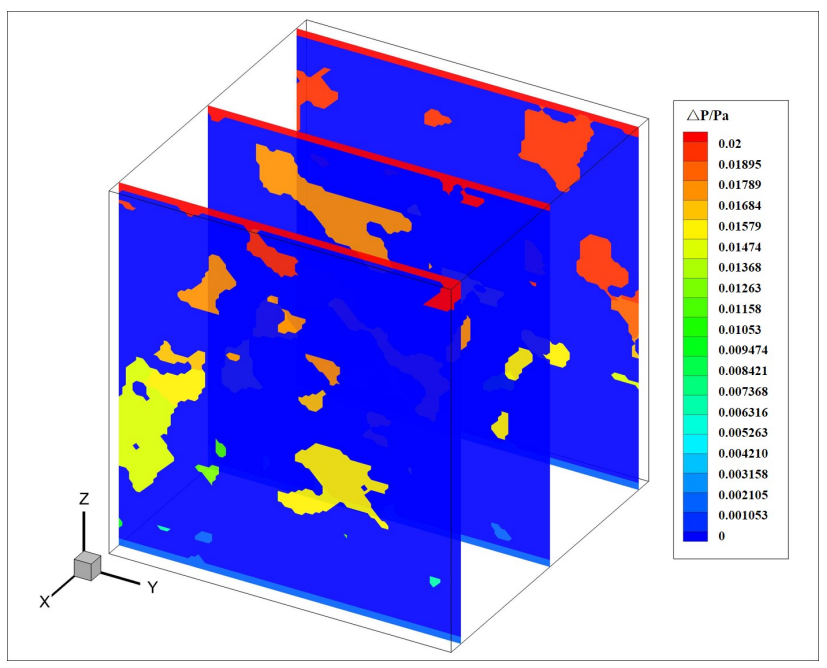

Figure 11: Pressure drop distribution on the shale digital core

\section{Gas transport mechanism judgement and permeability analysis}

\subsection{Gas flow regimes judgement of Sichuan Basin shale}

Firstly characteristic lengths are calculated by Equation (8) based on three-dimensional pore phase of shale digital cores shown in Figure 6. From the calculated results listed in Table 3, the average characteristic length for Sichuan Basin shale is $14.87 \mathrm{~nm}$. Subsequently, the average characteristic length is used in Equation (11) and Equation (12) to study the change in the Knudsen number under different formation pressure and temperature without adsorption effect and with adsorption effect. The relative degree of deviation is defined to study the free gas transport differences in the above two cases:

$$
\operatorname{dev}=\frac{\left|K_{n \_3 D}-K_{n \_3 D \_a d s}\right|}{K_{n \_3 D}} \times 100 \%
$$

The Knudsen number values in Figure 12, Figure 13 are compared with the Knudsen number values in Figure 1. It is can be seen that shale gas flow regimes mainly locate at the slip flow and transition flow region. The value of the relative degree of deviation is larger in high pore pressure than that in low pore pressure. However, the maximum value of the relative degree of deviation is $5 \%$. Therefore, the adsorption effect has no obvious influence on the free gas transport mechanism in the Sichuan Basin shale gas reservoir. 


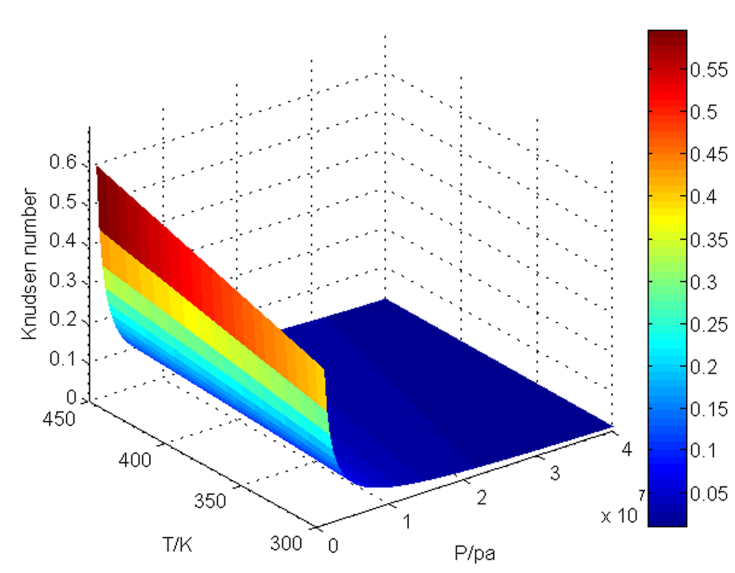

Figure 12: Knudsen number versus temperature and pressure with adsorption effects

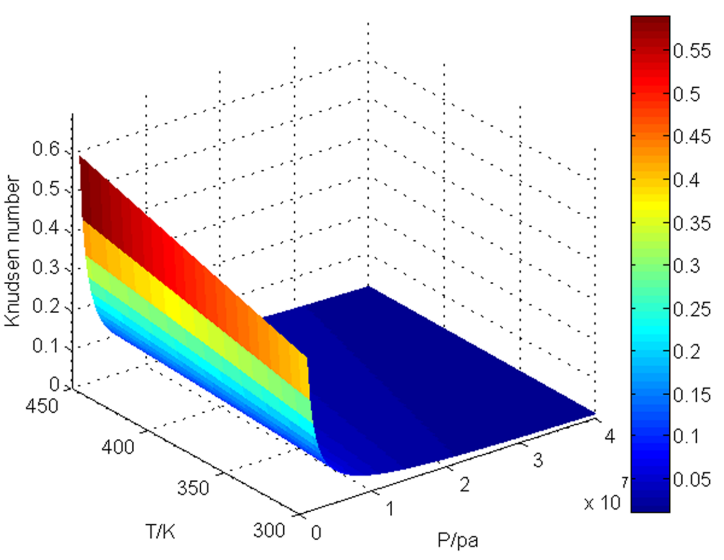

Figure 13: Knudsen number versus temperature and pressure without adsorption effects

Table 3: Characteristic lengths of anonymous shale formation, Sichuan Basin

\begin{tabular}{cc}
\hline Core number & Characteristic lengths $/ \mathbf{n m}$ \\
\hline 1 & 25.2127 \\
2 & 11.9197 \\
3 & 10.5176 \\
4 & 11.2995 \\
5 & 15.3914 \\
Average & 14.87 \\
\hline
\end{tabular}

\subsection{Gas flow regimes judgement based on three dimensional organic pores system and inorganic pores system}

Based on the aforementioned MCMC method, SEM images (Figure 15) in Haynesville shale [59] are used to reconstruct three-dimensional organic pores and inorganic pores. First we identify organic pores and inorganic pores by the pixel value of red and green colour. Then, the corresponding binary images can be obtained using the maximum class separation distance method proposed by Otsu [60]. Taking a pixel as the basic unit, the pixel value is set to 1 when the pixel is located in the matrix phase and the pixel value is set to 0 when the pixel is located in

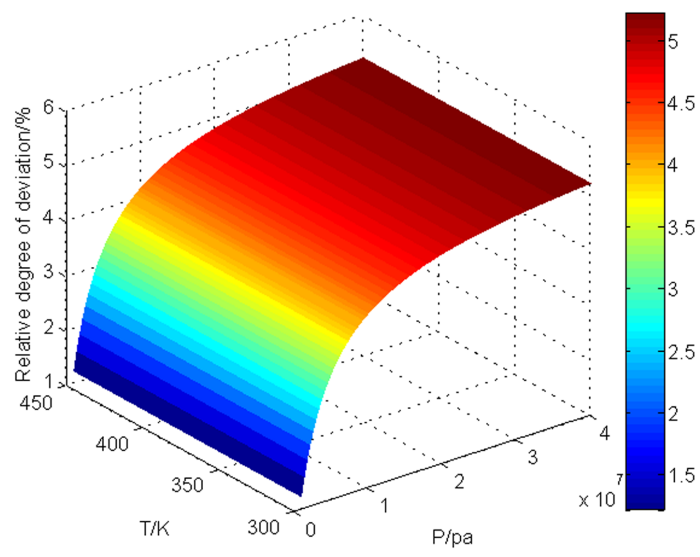

Figure 14: Relative degree of deviation comparing the above two results

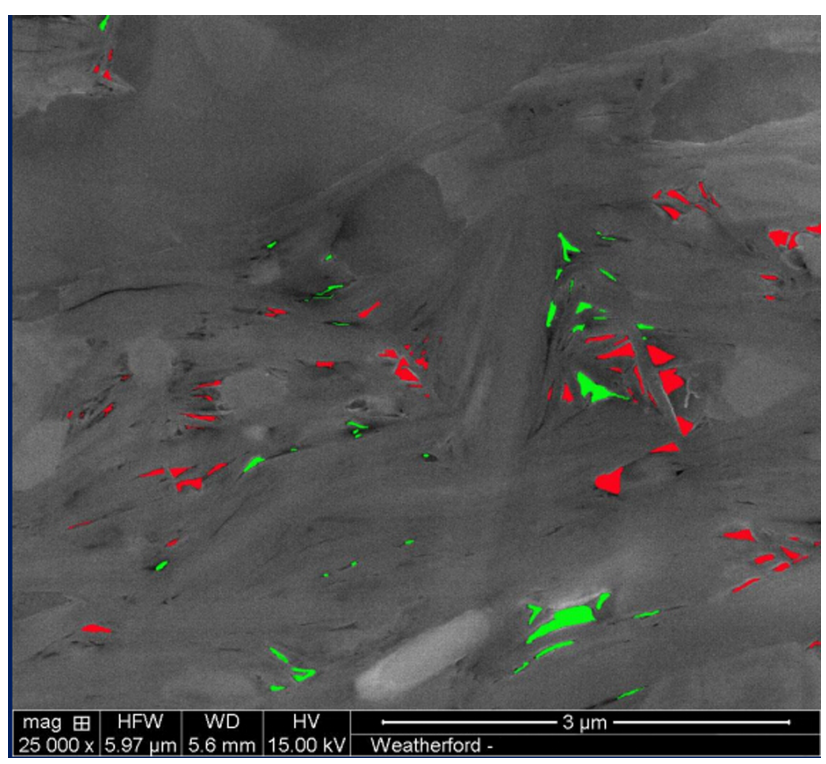

Figure 15: American Haynesville Shale SEM Image 


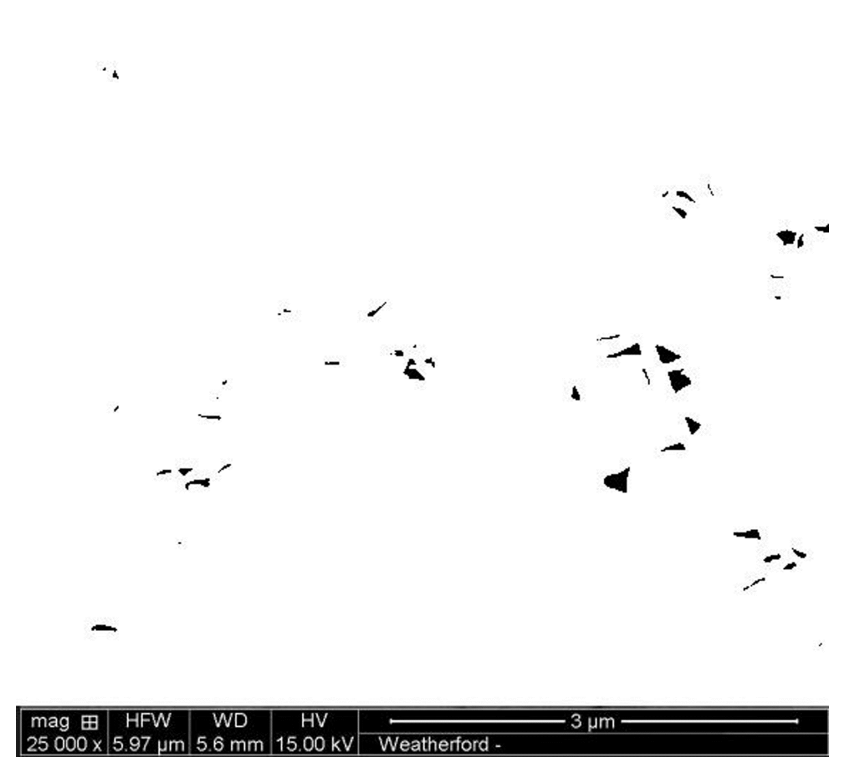

Figure 16: Binary image of inorganic pore in Haynesville shale rocks (white is the rock matrix, and black is the pore space)

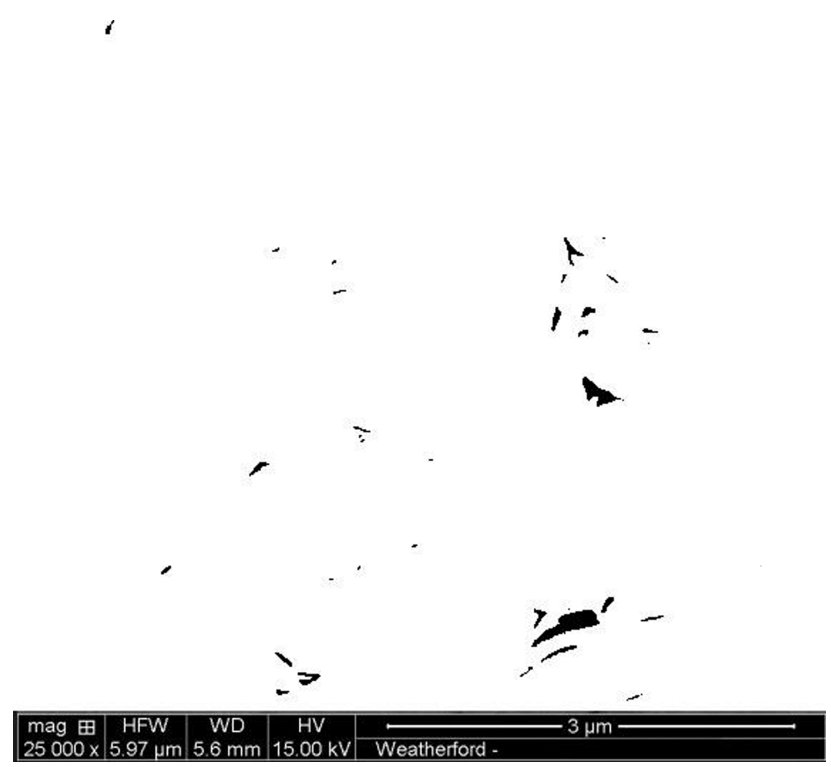

Figure 17: Binary image of organic pore in Haynesville shale rocks (white is the rock matrix, and black is the pore space)

the pore phase (Figure 16, Figure 17). Finally, the MCMC method is applied to reconstruct three-dimensional organic pores and inorganic pores based on binary images (Figure 18). The voxel sizes of the three-dimensional organic pores and inorganic pores are $800 \times 800 \times 800$.

Based on the statement that gas transports in the forms of free gas and adsorbed gas in organic pores and gas transports only in the form of free gas in inorganic pores, Equation (8) is applied to calculate the characteristic length without adsorption effect in three-dimensional

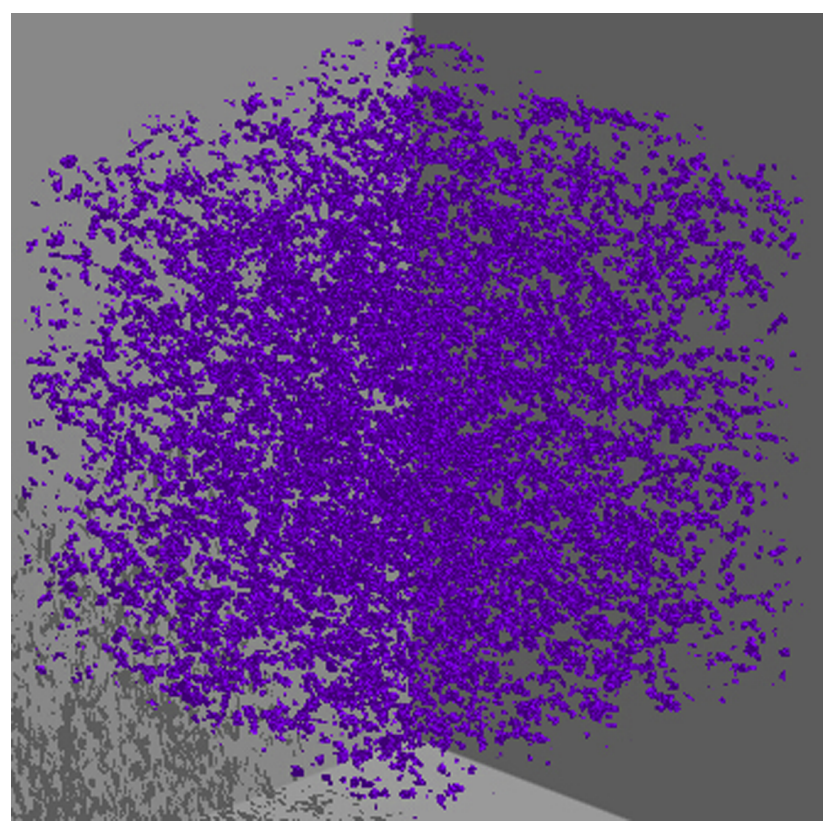

(a)

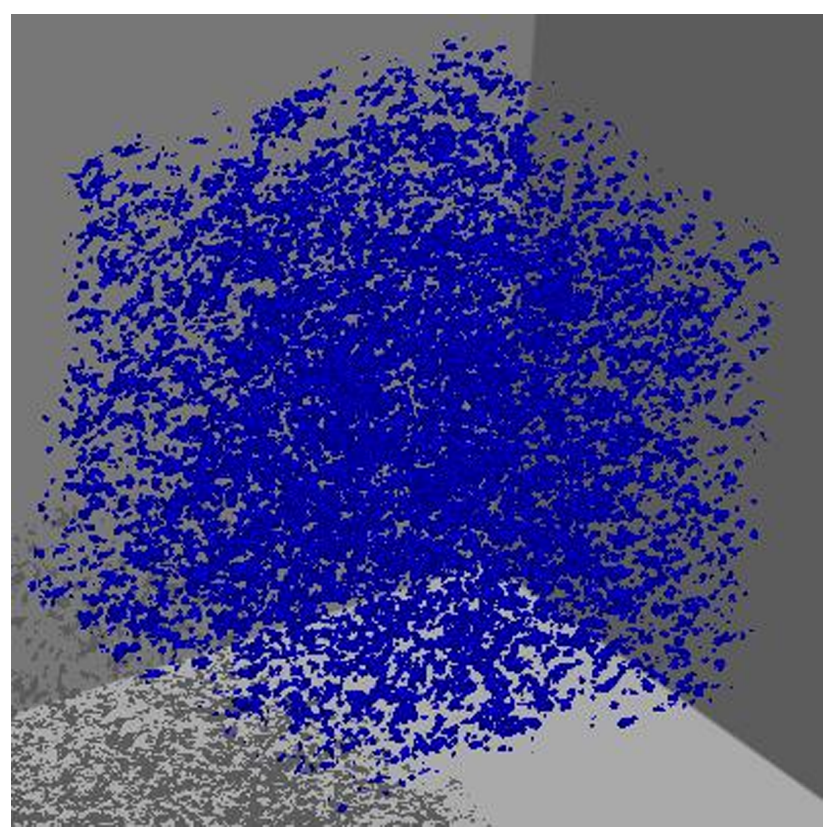

(b)

Figure 18: (a) Three dimensional inorganic pores (b) Three dimensional organic pores

inorganic pores and organic pores. Our calculation results indicate characteristic lengths without adsorption effect in three-dimensional inorganic pores and organic pores are $49.5 \mathrm{~nm}$ and $35 \mathrm{~nm}$ respectively. Then, the value of the characteristic length without adsorption effect in three-dimensional organic pores of $35 \mathrm{~nm}$ is revised by Equation (10) to consider the influence of the adsorption layer. Finally, Equation (11) and Equation (12) are used 


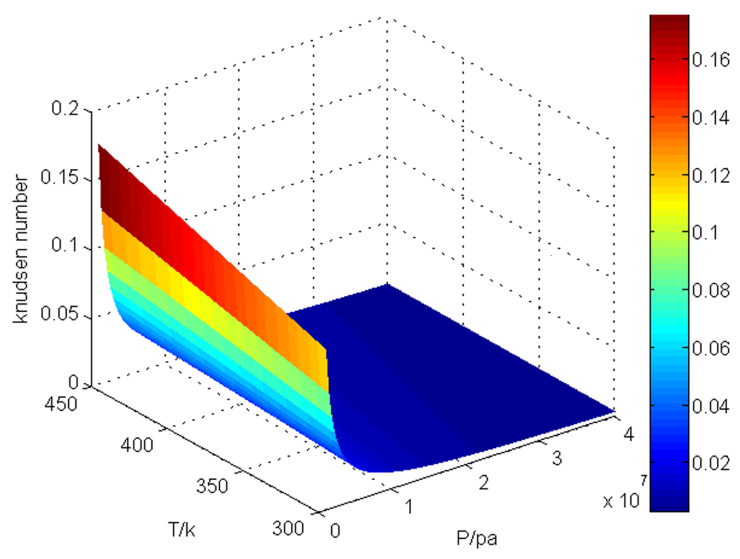

Figure 19: Knudsen number versus temperature and pressure in three dimensional organic pores

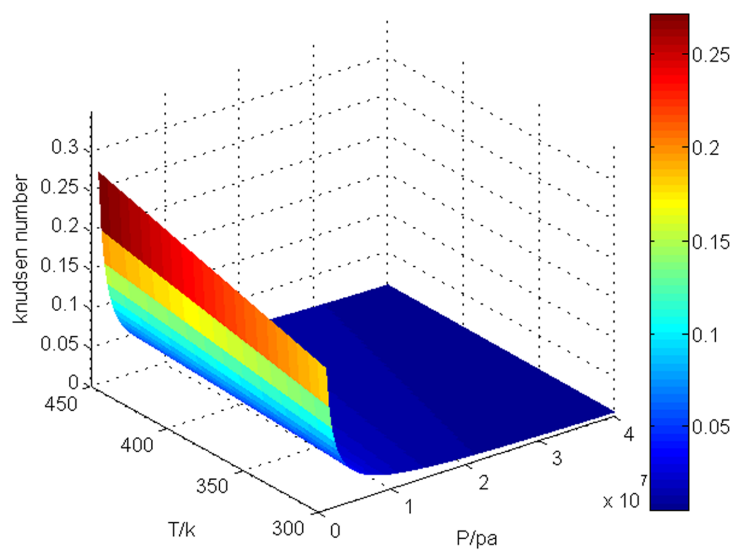

Figure 20: Knudsen number versus temperature and pressure in three dimensional inorganic pores

respectively to calculate the Knudsen number in threedimensional inorganic pores and organic pores. In Figure 19 and Figure 20, the Knudsen number differs a litthe in low pore pressure $(<5 \mathrm{MPa})$. But for shale gas reservoirs, pore pressure usually ranges from $10 \mathrm{MPa}$ to $40 \mathrm{MPa}$ [61] and the Knudsen number is almost the same in threedimensional organic pores and inorganic pores under this condition. Therefore, free gas flow regimes can be deemed as the same in inorganic pores and organic pores. This may indicate that in macro scale gas flow numerical simulation, inorganic pores and organic pores can be viewed as a continuous system and a dual medium (matrix-micro fracture) mathematical model is suitable to simulate the shale gas production process.

\subsection{Shale gas permeability at different reservoir conditions}

According to Equation (10), Equation (12) and Equation (19), free gas permeability in consideration of adsorption can be given as:

$$
k_{\text {free }}=\frac{\phi l_{c}^{2}\left(P_{g}\right)}{32 \tau} f\left(K_{n \_3 D \_a d s}\right)
$$

Surface diffusion takes place within the adsorbed gas to enhance the transport of gas molecules along molecular concentration gradients [62]. Based on Hwang and Kammermeyer's model [63], combined with methane adsorption experimental data, the surface diffusion coefficient for methane $D_{s 0}$ when gas coverage is zero can be expressed as:

$$
D_{s 0}=8.29 \times 10^{-7} T^{0.5} \exp \left(-\frac{\Delta H^{0.8}}{R T}\right)
$$

The isosteric adsorption heat $\Delta H$ is a function of gas coverage. According to Equation (25), the isosteric adsorption heat and gas coverage have a linear relationship and can be given as [64]:

$$
\Delta H=\eta \theta+\Delta H(0)
$$

The surface diffusion coefficient in Equation (24) is obtained under a low pressure condition by theory and experiments, and is a function of gas molecular weight, temperature, and gas activation energy, isosteric adsorption heat and is independent of pressure [63]. In order to describe the gas surface diffusion in nanopores of shale gas reservoirs under a high pressure condition, the influence of gas coverage on surface diffusion is considered. Chen et al. [65] used the kinetic method to calculate the surface diffusion coefficient:

$$
\begin{gathered}
D_{s}= \\
D_{s 0} \frac{(1-\theta)+\frac{\kappa}{2} \theta(2-\theta)+\{H(1-\kappa)\}(1-\kappa) \frac{\kappa}{2} \theta^{2}}{\left(1-\theta+\frac{\kappa}{2} \theta\right)^{2}} \\
\quad H(1-\kappa)=0, \quad \kappa \geq 1 ; \quad 1,0 \leq \kappa \leq 1
\end{gathered}
$$

Where $H(1-\kappa)$ is Heaviside function. The surface diffusion coefficient at different pressure and temperature conditions is calculated according to Equation (26). Surface diffusion of adsorbed gas molecules can be modelled as the general diffusion process, using the molar flow rate per unit area of the concentration gradient within the adsorbed monolayer as developed in [62]:

$$
J_{a}=D_{s} \frac{d C_{a}}{d x}
$$


$C_{a}$ is calculated assuming Langmuir adsorption and is given by:

$$
C_{a}=C_{a \max } \theta
$$

$C_{a m a x}$ can be expressed as [66]:

$$
C_{a \max }=\frac{C_{\max }}{\varepsilon_{k s}}
$$

Combining Equation (28) and Equation (29), molar flow rate in the adsorbed layer is then expressed below:

$$
J_{A}=D_{s} C_{a \max } \frac{d \theta}{d p} \pi\left(l_{c}^{2}-l_{c}^{2}\left(P_{g}\right)\right) \frac{d p}{d x}
$$

From Equation (31), volumetric flow rate $V_{A}$ is:

$$
V_{A}=\frac{M}{\rho} D_{s} C_{a \max } \frac{d \theta}{d p} \pi\left(l_{c}^{2}-l_{c}^{2}\left(P_{g}\right)\right) \frac{d p}{d x}
$$

According to Equation (26) and the Darcy law, adsorbed gas permeability can be written as:

$$
k_{\text {surface }}=\frac{\phi \mu M}{\tau \rho} D_{s} C_{a \max } \frac{d \theta}{d p}\left(1-\left(\frac{l_{c}\left(P_{g}\right)}{l_{c}}\right)^{2}\right)
$$

Shale gas permeability in Equation (34) can be derived by combining free gas permeability in consideration of adsorption by Equation (23) with surface diffusion of adsorbed gas by Equation (33). Typical shale gas reservoir

\begin{tabular}{|c|c|}
\hline Properties & Value \\
\hline Porosity & 0.1 \\
\hline Tortuosity & 2.3 \\
\hline Characteristic length $l_{c} / \mathrm{m}$ & $1.487 \times 10^{-8}$ \\
\hline $\begin{array}{l}\text { Total organic grain volume per total } \\
\text { grain volume } \epsilon_{k s}\end{array}$ & $0.01[66]$ \\
\hline Langmuir pressure $p_{L} / \mathrm{MPa}$ & $13.789514[66]$ \\
\hline $\begin{array}{c}\text { Maximum adsorbed gas } \\
\text { concentration } C_{\max } / \mathrm{mol} / \mathrm{m}^{3}\end{array}$ & $328.7[66]$ \\
\hline $\begin{array}{l}\text { Isosteric adsorption heat at zero gas } \\
\text { coverage } \Delta H(0) / \mathrm{J} / \mathrm{mol}\end{array}$ & $16000[67]$ \\
\hline $\begin{array}{c}\text { Fitting coefficients of isosteric } \\
\text { adsorption heat } \gamma / \mathrm{J} / \mathrm{mol}\end{array}$ & $-4186[67]$ \\
\hline Ideal gas constant $R / \mathrm{J} /(\mathrm{mol} \cdot \mathrm{k})$ & 8.314 \\
\hline $\begin{array}{l}\text { Ratio of the rate constant for blockage } \\
\text { to the rate constant for forward } \\
\text { migration } \kappa \text {, dimensionless }\end{array}$ & $0.5[67]$ \\
\hline Molecular weight $M / \mathrm{kg} / \mathrm{mol}$ & 0.016 \\
\hline
\end{tabular}
parameters are given in Table 4. Figure 21 shows that gas permeability increases with the decrease of pressure and the increase of temperature. The gas permeability value

Table 4: Typical shale gas reservoir parameters

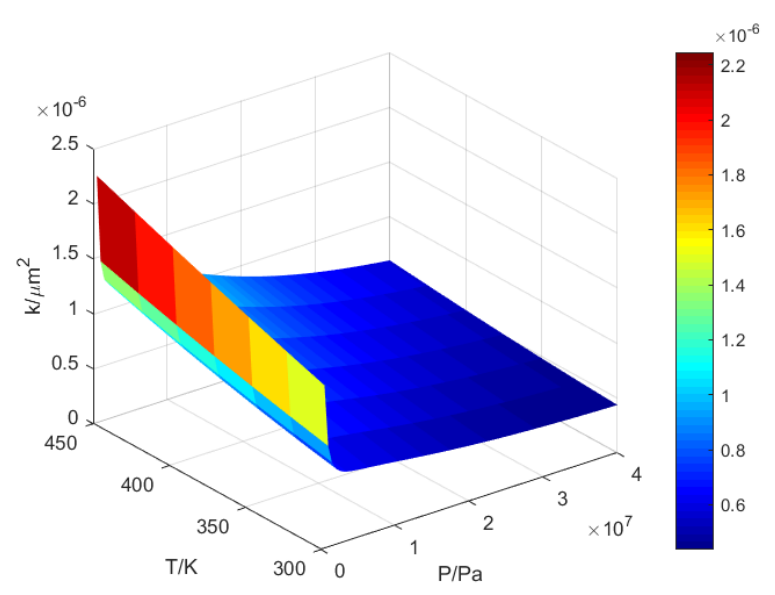

Figure 21: Shale gas permeability versus temperature and pressure

ranges from $4.3685 \times 10^{-7} \mu \mathrm{m}^{2}$ to $2.2451 \times 10^{-6} \mu \mathrm{m}^{2}$ for different reservoir conditions.

$$
\begin{aligned}
k_{\mathrm{t}} & =\frac{\phi l_{c}^{2}\left(P_{g}\right)}{32 \tau} f\left(K_{n_{-} 3 D_{-} a d s}\right) \\
& +\frac{\phi \mu M}{\tau \rho} D_{s} C_{a \max } \frac{d \theta}{d p}\left(1-\left(\frac{l_{c}\left(P_{g}\right)}{l_{c}}\right)^{2}\right)
\end{aligned}
$$

\section{Conclusions}

A method to judge shale gas flow regimes based on digital core analysis is studied. A Voxel-based method is proposed to the calculate characteristic length of a threedimensional shale digital core. The Knudsen number for MCMC reconstructed three-dimensional shale digital core is calculated by the ratio of the molecular mean free path to the characteristic length and is used to judge the gas flow regime under different reservoir conditions. The results indicate that shale gas flow regimes mainly locate at the slip flow and transition flow region. Furthermore, adsorption has no obvious influence on the free gas flow regimes. Moreover, free gas flow regimes in organic pores and inorganic pores are judged. Our analysis results show that free gas flow regimes can be deemed as the same in two different pore systems and inorganic-organic pores can be viewed as the continuous system in a macro scale gas flow simulation. Gas permeability increases with the decrease of pressure and the increase of temperature.

Acknowledgement: This project was supported by the National Natural Science Foundation of China (No. 51504276, No.51490654), the Fundamental Research Funds for the Central Universities (No.16CX05018A, No. 18CX06008A), 
the Major Projects of the National Science and Technology (2016ZX05061), Graduate School Innovation Program of China University of Petroleum (YCX2017019).

Conflict of Interests: The authors declare no conflict of interest.

\section{Nomenclature}

$\epsilon_{k s} \quad$ total organic grain volume per total grain volume, dimensionless

$\kappa$

$\Delta H(0) \quad$ isosteric adsorption heat at zero gas coverage $(\mathrm{J} / \mathrm{mol})$

$\eta$

fitting coefficients of isosteric adsorption heat $(\mathrm{J} / \mathrm{mol})$

$\gamma \quad$ resolution $(\mathrm{m})$

$\lambda \quad$ mean free path of molecules(m)

$\mu \quad$ viscosity $(\mathrm{Pa} \cdot \mathrm{s})$

$\Phi \quad$ porosity, dimensionless

$\rho \quad$ gas density $\left(\mathrm{kg} / \mathrm{m}^{3}\right)$

$\tau \quad$ tortuosity, dimensionless

$\theta \quad$ gas coverage on the pore wall, dimensionless

A cross section area of shale digital core $\left(\mathrm{m}^{2}\right)$

$C_{\text {amax }}$ maximum adsorbed gas concentration inside the organic matter $\left(\mathrm{mol} / \mathrm{m}^{3}\right)$

$C_{a} \quad$ adsorbed gas concentration $\left(\mathrm{mol} / \mathrm{m}^{3}\right)$

$C_{\text {max }} \quad$ maximum adsorbed gas concentration inside the total core sample $\left(\mathrm{mol} / \mathrm{m}^{3}\right)$

$d_{m} \quad$ gas molecular diameter $(\mathrm{m}) 4 \times 10^{-10}$

$D_{s 0} \quad$ surface diffusion coefficient when gas coverage is zero $\left(\mathrm{m}^{2} / \mathrm{s}\right)$

$D_{s} \quad$ surface diffusion coefficient $\left(\mathrm{m}^{2} / \mathrm{s}\right)$

dev relative degree of deviation, dimensionless

$J_{a} \quad$ molar flow rate per unit area $\left(\mathrm{mol} /\left(\mathrm{m}^{2} \cdot \mathrm{s}\right)\right)$

$k_{B} \quad$ Boltzmann constant $(\mathrm{J} / \mathrm{K}), 1.3805 \times 10^{-23}$

$K_{n \_3 D \_a d s} \quad$ Knudsen number with adsorption effect

$K_{n \_3 D} \quad$ Knudsen number without adsorption effect

$K_{n} \quad$ Knudsen number, dimensionless

$k \quad$ permeability $\left(\mu \mathrm{m}^{2}\right)$

$l_{c_{-} 3 D} \quad$ characteristic length of three dimensional pore phases $(\mathrm{m})$

$l_{c} \quad$ characteristic length $(\mathrm{m})$

$l_{c}\left(P_{g}\right) \quad$ characteristic length of three dimensional pore phases with adsorption effect(m)

$M_{g} \quad$ gas molecular weight (g/mol)

$N(i j k) \quad$ neighbor of $(i, j, k)$

$n \quad$ voxel number
$P_{g} \quad$ pore pressure( $\left.\mathrm{MPa}\right)$

$p_{L} \quad$ Langmuir pressure( $\left.\mathrm{MPa}\right)$

$p(z) \quad$ chord length distribution function in pore phase, dimensionless

gas flux $\left(\mathrm{m}^{3} / \mathrm{s}\right)$

single tube radius $(\mathrm{m})$

certain voxel, dimensionless

time(s)

gas velocity $(\mathrm{m} / \mathrm{s})$

rectangular parallelepiped array of voxels

rectangular grid filled with cube voxels, dimensionless

$X(t) \quad$ Markov process

$z_{-}$vol chord length based on voxel unit in three dimensional digital image

chord length (m)

\section{References}

[1] Zhang K., Ma X., Li Y, et al., Parameter prediction of hydraulic fracture for tight reservoir based on micro-seismic and history 65 matching, Fractals, 2018: 1840009.

[2] Zhang K., Zhang X., Zhang L, et al., Assisted history matching for the inversion of fractures based on discrete fracturematrix model with different combinations of inversion parameters, Computational Geosciences, 2017, 21(5-6): 1365-1383.

[3] Wang L., Wang S., Zhang R, et al., Review of multi-scale and multi-physical simulation technologies for shale and tight gas reservoirs, Journal of Natural Gas Science and Engineering, 2017, 37: 560-578.

[4] Singh H., Javadpour F. Langmuir slip-Langmuir sorption permeability model of shale, Fuel, 2016, 164: 28-37.

[5] Ma J., Couples G. D., Jiang Z, et al., Predicting the Effective Gas Flow Properties of Gas Shale, from Nano-Pores to Shale Parasequences, (12-14 August, Denver 2013, Colorado, USA), Proceedings of URTEC: Unconventional Resources Technology Conference, Society of Petroleum Engineers, 2013.

[6] Song W., Yao J., Ma J, et al., Pore-scale numerical investigation into the impacts of the spatial and pore-size distributions of organic matter on shale gas flow and their implications on multiscale characterisation, Fuel, 2018, 216: 707-721.

[7] Zhu H., Ju Y., Lu W, et al., The Characteristics and Evolution of Micro-Nano Scale Pores in Shales and Coals, Journal of Nanoscience and Nanotechnology, 2017, 17(9): 6124-6138.

[8] Zou C., Zhu R., Wu S, et al., Types, characteristics, genesis and prospects of conventional and unconventional hydrocarbon accumulations: Taking tight oil and tight gas in China as an instance, Acta Petrolei Sinica, 2012, 33(2): 173-187.

[9] Loucks R. G., Reed R. M., Ruppel S. C, et al., Morphology, genesis, and distribution of nanometer-scale pores in siliceous mudstones of the Mississippian Barnett Shale, Journal of sedimentary research, 2009, 79(12): 848-861.

[10] Wang F. P., Reed R. M., Pore networks and fluid flowin gas shales, (4-7 October, 2009, New Orleans, Louisiana, USA), Proceedings of the SPE Annual Technical Conference and Exhibi- 
tion, Society 14 Ë W. Song et al. of Petroleum Engineers, 2009.

[11] Ma J., Sanchez J. P., Wu K, et al., A pore network model for simulating non-ideal gas flow in micro- and nano-porous materials, Fuel, 2014, 116(Supplement C): 498-508.

[12] Ma J., Couples G. D., Zhao X, et al., Assessing Impact of Shale Gas Adsorption on Free-Gas Permeability via a Pore Network Flow Mode, (20-22 July, 2015, San Antonio, Texas, USA), Proceedings of, URTEC: Unconventional Resources Technology Conference, Society of Petroleum Engineers, 2015.

[13] Riewchotisakul S., Akkutlu I. Y. Adsorption-Enhanced Transport of Hydrocarbons in Organic Nanopores, SPE Journal, 2016, 21(07): 1960-1969.

[14] Ho C.-M., Tai Y.-C. Micro-electro-mechanical-systems (MEMS) and fluid flows, Annual Review of Fluid Mechanics, 1998, 30(1): 579-612.

[15] Song W., Yao J., Li Y, et al., Apparent gas permeability in an organic-rich shale reservoir, Fuel, 2016, 181: 973-984.

[16] Song W., Yao J., Ma J, et al., Assessing relative contributions of transport mechanisms and real gas properties to gas flow in nanoscale organic pores in shales by pore network modelling, International Journal of Heat and Mass Transfer, 2017, 113: 524537.

[17] Ziarani A. S., Aguilera R. Knudsen's permeability correction for tight porous media, Transport in Porous Media, 2012, 91(1): 239260.

[18] Civan F. Effective correlation of apparent gas permeability in tight porous media, Transport in Porous Media, 2010, 82(2): 375-384.

[19] Lin D., Wang J., Yuan B, et al., Review on gas flow and recovery in unconventional porous rocks, Adv Geo-Energy Res, 2017, 1: 39-53.

[20] Javadpour F., Nanopores and apparent permeability of gas flow in mudrocks (shales and siltstone), Journal of Canadian Petroleum Technology, 2009, 48(08): 16-21.

[21] Darabi H., Ettehad A., Javadpour F, et al., Gas flow in ultra-tight shale strata, Journal of Fluid Mechanics, 2012, 710: 641-658.

[22] Beskok A., Karniadakis G. E., Report: a model for flows in channels, pipes, and ducts at micro and nano scales, Microscale Thermophysical Engineering, 1999, 3(1): 43-77.

[23] Civan F., Devegowda D., Sigal R. F., Critical evaluation and improvement of methods for determination of matrix permeability of shale,(1-2 September October, 2013, New Orleans, Louisiana, USA), Proceedings of the SPE Annual Technical Conference and Exhibition, Society of Petroleum Engineers, 2013.

[24] Civan F., Rai C. S., Sondergeld C. H., Shale-gas permeability and diffusivity inferred by improved formulation of relevant retention and transport mechanisms, Transport in Porous Media, 2011, 86(3): 925-944

[25] Freeman C., Moridis G., Blasingame T., A numerical study of mi50 croscale flow behavior in tight gas and shale gas reservoir systems, Transport in Porous Media, 2011, 90(1): 253.

[26] Landry C. J., Prodanović M., Eichhubl P., Direct simulation of supercritical gas flow in complex nanoporous media and prediction of apparent permeability, International Journal of Coal Ge55 ology, 2016, 159: 120-134.

[27] Wu K., Chen Z., Li X, et al., A model for multiple transport mechanisms through nanopores of shale gas reservoirs with real gas effect-adsorption-mechanic coupling, International Journal of Heat and Mass Transfer, 2016, 93: 408-426.
[28] Sun H., Yao J., Cao Y.-c, et al., Characterization of gas transport behaviors in shale gas and tight gas reservoirs by digital rock analysis, International Journal of Heat and Mass Transfer, 2017, 104: 227-239.

[29] Ilgen A. G., Heath J. E., Akkutlu I. Y, et al., Shales at all scales: Exploring coupled processes in mudrocks, Earth-Science Reviews, 2017, 166: 132-152.

[30] Song W., Yao J., Li Y, et al., Fractal models for gas slippage factor in porous media considering second-order slip and surface adsorption, International Journal of Heat and Mass Transfer, 2018, 118: 948-960.

[31] Wang C., Yao J., Wu K, et al., Pore-scale characterization of carbonate rock heterogeneity and prediction of petrophysical properties, (27-30 August, 2012, Aberdeen, Scotland, UK), Proceedings of the International Symposium of the Society of Core Analysts, 2012.

[32] Jian-Chao C., A fractal approach to low velocity non-Darcy flow in a low permeability porous medium, Chinese Physics B, 2014, 23(4): 044701.

[33] Yao J., Wang C., Yang Y, et al., The construction of carbonate digital rock with hybrid superposition method, Journal of Petroleum Science and Engineering, 2013, 110: 263-267.

[34] Cai J., Luo L., Ye R, et al., Recent advances on fractal modeling of permeability for fibrous porous media, Fractals, 2015, 23(01): 1540006.

[35] Chen D., Yao Y., Fu G, et al., A new model for predicting liquid loading in deviated gas wells, Journal of Natural Gas Science and Engineering, 2016, 34: 178-184.

[36] Xia Y., Cai J., Wei W, et al., A new method for calculating fractal dimensions of porous media based on pore size distribution, Fractals, 2018, 26(01): 1850006.

[37] Guo X., Li Y., Liu R, et al., Characteristics and controlling factors of micropore structures of the Longmaxi Shale in the Jiaoshiba area, Sichuan Basin, Natural Gas Industry B, 2014, 1(2): 165-171.

[38] Jiao K., Yao S., Liu C, et al., The characterization and quantitative analysis of nanopores in unconventional gas reservoirs utilizing FESEM-FIB and image processing: An example from the lower Silurian Longmaxi Shale, upper Yangtze region, China, International Journal of Coal Geology, 2014, 128: 1-11.

[39] Liang C., Jiang Z., Zhang C, et al., The shale characteristics and shale gas exploration prospects of the Lower Silurian Longmaxi shale, Sichuan Basin, South China, Journal of Natural Gas Science and Engineering, 2014, 21: 636-648.

[40] Shi M., Yu B., Xue Z, et al., Pore characteristics of organicrich shales with high thermal maturity: A case study of the Longmaxi gas shale reservoirs from well Yuye-1 in southeastern Chongqing, China, Journal of Natural Gas Science and Engineering, 2015, 26: 948-959.

[41] Song W., Yao J., Li Y, et al., New pore size distribution calculation model based on chord length and digital image, Journal of Natural Gas Science and Engineering, 2017, 48, 111-118.

[42] Milliken K. L., Rudnicki M., Awwiller D. N, et al., Organic matterhosted pore system, Marcellus formation (Devonian), Pennsylvania, AAPG bulletin, 2013, 97(2): 177-200.

[43] Bai B., Elgmati M., Zhang H, et al., Rock characterization of Fayetteville shale gas plays, Fuel, 2013, 105: 645-652.

[44] Song W., Yao J., Ma J, et al., Numerical simulation of multiphase flow in nanoporous organic matter with application to coal and gas shale systems, Water Resources Research, 2018, 54(2): 1077-1092. 
[45] Geman S., Geman D., Stochastic relaxation, Gibbs distributions, and the Bayesian restoration of images, Pattern Analysis and Machine Intelligence, IEEE Transactions on, 1984, (6): 721 . 741.

[46] Wu K., Van Dijke M. I., Couples G. D, et al., 3D stochastic modelling of heterogeneous porous media-applications to reservoir rocks, Transport in Porous Media, 2006, 65(3): 443-467.

[47] Yang Y., Yao J., Wang C, et al., New pore space characterization method of shale matrix formation by considering organic and inorganic pores, Journal of Natural Gas Science and Engineering, 2015, 27: 496-503.

[48] Lu B., Torquato S., Chord-length and free-path distribution functions for many-body systems, The Journal of chemical physics, 1993, 98(8): 6472-6482.

[49] Torquato S., Random heterogeneous materials: microstructure and macroscopic properties[M]. Springer Science \& Business Media, 2013:

[50] Javadpour F., Fisher D., Unsworth M., Nanoscale gas flow in shale gas sediments, Journal of Canadian Petroleum Technology, 2007, 46(10):55-61.

[51] Zalc J. M., Reyes S. C., Iglesia E., The effects of diffusion mechanism and void structure on transport rates and tortuosity factors in complex porous structures, Chemical Engineering Science, 2004, 59(14): 2947-2960.

[52] Levitz P., Knudsen diffusion and excitation transfer in random porous media, The Journal of Physical Chemistry, 1993, 97(15): 3813-3818.

[53] Heller R., Zoback M. Adsorption of methane and carbon dioxide on gas shale and pure mineral samples, Journal of Unconventional Oil and Gas Resources, 2014, 8: 14-24.

[54] Zhao J., Yao J., Zhang M, et al., Study of gas flow characteristics in tight porous media with a microscale lattice boltzmann model, Scientific Reports, 2016, 6: 32393.

[55] Suga K., Takenaka S., Ito T, et al., Evaluation of a lattice Boltzmann method in a complex nanoflow, Physical Review E, 2010, 82(1): 016701
[56] Li Q., He Y., Tang G, et al., Lattice Boltzmann modeling of microchannel flows in the transition flow regime, Microfluidics and nanofluidics, 2011, 10(3): 607-618.

[57] Tang G., TaoW., He Y., Lattice Boltzmann method for gaseous microflows using kinetic theory boundary conditions, Physics of 40 Fluids, 2005, 17(5): 058101.

[58] Karniadakis G., Beskok A., Aluru N., Microflows and nanoflows: fundamentals and simulation[M]. Springer Science \& Business Media, 2006.

[59] Rine J., Dorsey W., Floyd M, et al., A Comparative SEM Study of Pore Types and Porosity Distribution in High to Low Porosity Samples from Selected Gas-Shale Formations, Gulf Coast Association of Geological Societies Transactions, 2010, 60:825.

[60] Otsu N., A threshold selection method from gray-level histograms, Automatica, 1975, 11(285-296): 23-27.

[61] Freeman C., Moridis G., Blasingame T., A numerical study of microscale flow behavior in tight gas and shale gas reservoir systems, Transport in Porous Media, 2011, 90(1): 253-268.

[62] Cunningham R. E., Williams R., Diffusion in gases and porous media[M]. Springer, 1980.

[63] Hwang S. T., Kammermeyer K., Surface diffusion in microporous media, The Canadian Journal of Chemical Engineering, 1966, 44(2): 82-89.

[64] Nodzeński A., Sorption and desorption of gases (CH4, $\mathrm{CO} 2)$ on hard coal and active carbon at elevated pressures, Fuel, 1998, 77(11): 1243-1246

[65] Chen Y. D., Yang R. T., Concentration dependence of surface diffusion and zeolitic diffusion, AIChE Journal, 1991, 37(10): 15791582.

[66] Wasaki A., Akkutlu I. Y., Permeability of organic-rich shale, SPE Journal, 2015, 20(06): 1,384-381,396.

[67] Wu K., Li X., Wang C, et al., Model for surface diffusion of adsorbed gas in nanopores of shale gas reservoirs, Industrial \& Engineering Chemistry Research, 2015, 54(12): 3225-3236. 